\title{
Pollen morphology of the genus Curcuma (Zingiberaceae) in Northeastern Thailand
}

\author{
Piyaporn Saensouk $^{\mathrm{a}, *}$, Piyada Theerakulpisut ${ }^{\mathrm{b}}$, Achra Thammathaworn ${ }^{\mathrm{c}}$, Surapon Saensouk ${ }^{\mathrm{d}}$, \\ Charun Maknoi ${ }^{e, f}$, Pimjai Kohkaew ${ }^{\mathrm{e}, \mathrm{f}}$ \\ a Plant and Invertebrate Taxonomy and its Application Research Unit, Department of Biology, \\ Faculty of Science, Mahasarakham University, Mahasarakham 44150 Thailand \\ b Applied Taxonomic Research Center, Department of Biology, Faculty of Science, Khon Kaen University, \\ Khon Kaen 40002 Thailand \\ c Office of General Education, Khon Kaen University, Khon Kaen 40002 Thailand \\ ${ }^{d}$ Plant and Invertebrate Taxonomy and its Application Research Unit, \\ Walai Rukhavej Botanical Research Institute, Mahasarakham University, Mahasarakham 44150 Thailand \\ e Queen Sirikit Botanic Garden, Mae Rim, Chiang Mai 50180 Thailand \\ f Nong Khai Campus, Khon Kaen University, Nong Khai 43000 Thailand
}

*Corresponding author, e-mail: pcornukaempferia@yahoo.com

Received 8 Mar 2014

Accepted 30 Jun 2015

\begin{abstract}
The palynological study of 14 species of Curcuma, namely C. alismatifolia Gagnep. 1, C. alismatifolia Gagnep. 2, C. alismatifolia Gagnep. 3, C. alismatifolia Gagnep. 4, C. alismatifolia Gagnep. 5, C. alismatifolia Gagnep. 6, C. angustifolia Roxb., C. gracillima Gagnep., C. harmandii Gagnep., C. larsenii Maknoi \& Jenjitt, C. longa L. 1, C. longa L. 2, C. petiolata Roxb., C. parviflora Wall, C. cf. parviflora, C. pierreana Gagnep., C. rhabdota Sirirugsa \& Newman., C. rubescens Roxb., C. singularis Gagnep., and C. sparganifolia Gagnep., was undertaken using a light microscope and scanning electron microscope. The pollen grains were monad, inaperturate, with radial symmetry and large with rugulose exine sculpturing. Pollen grains had various shapes (subspheroidal, prolate spheroidal, spheroidal, subprolate, and prolate). Pollen shape can be used as a supplementary character for identification of the Curcuma species. In the present study, the pollen morphology of 13 species of Curcuma is recorded for the first time.
\end{abstract}

KEYWORDS: palynology, ginger family, scanning electron microscope

\section{INTRODUCTION}

The Zingiberaceae is a large family including about 50 genera and 1400 species that are distributed mainly in the tropics from India to Malaysia. Kress et $\mathrm{al}^{1}$ proposed a new classification system for the Zingiberaceae based on molecular phylogeny. They divided Zingiberaceae into 4 subfamilies and 6 tribes: Alpinioideae (Alpinieae \& Riedelieae), Siphonochiloideae (Siphonochileae), Tamijioideae (Tamijieae), and Zingiberoideae (Zingibereae \& Globbeae). The genus Curcuma was placed in the subfamily Zingiberoideae (tribe Zingibereae) which included the genera Boesenbergia, Camptandra, Cautleya, Cornukaempferia, Curcuma, Curcumorpha, Distichochlamys, Haniffia, Haplochorema, Hedychium, Hitchenia, Kaempferia, Laosanthus, Nanochilus, Paracautleya, Parakaempferia, Pommereschea, Pyrgophyllum, Rhynchanthus,
Roscoea, Scaphochlamys, Smitharis, Stadiochilus, Stahlianthus, and Zingiber. In Thailand, the family Zingiberaceae includes about 26 genera and 300 species $^{2}$. The genus Curcuma consists of 34 species in Thailand and 60 species worldwide ${ }^{2}$. Maknoi $^{3}$ found 8 taxa of the genus Curcuma in Northeastern Thailand. The keys to the genus Curcuma are short and wide corolla tube short, flowers of various colours, with leaf-blade tapering into petiole $^{2}$. Maknoi ${ }^{3}$ divided the plants in the genus Curcuma into 5 groups based on morphological characters. Some species of this genus have great ornamental values, e.g., C. alismatifolia, C. petiolata, C. pierreana, C. rhabdota, and C. sparganifolia. Numerous selected clones are now widely cultivated in Southeast Asia as "Siamese Tulip". The plants in this genus has been widely cultivated and commercialized in Europe and the USA under various names, e.g., "Pink Curcuma". The flowers have various 
Table 1 Specimens of the genus Curcuma investigated, and their pollen morphology data.

\begin{tabular}{|c|c|c|c|c|c|}
\hline \multirow[t]{2}{*}{ Taxa } & \multirow[t]{2}{*}{ Remark } & \multirow[t]{2}{*}{ Vouchers } & \multirow[t]{2}{*}{ Shape } & \multicolumn{2}{|c|}{ Size (mean \pm SD $\mu \mathrm{m})$} \\
\hline & & & & Polar axis & Equatorial axis \\
\hline C. alismatifolia Gagnep. 1 & pink bract (cultivated) & P. Kohkaew 01/53 & prolate spheroidal & $70.1 \pm 4.2$ & $66.7 \pm 4.5$ \\
\hline C. alismatifolia Gagnep. 2 & with pink bract (cultivated) & P. Kohkaew 02/53 & subprolate & $56.1 \pm 4.2$ & $45.1 \pm 3.7$ \\
\hline C. alismatifolia Gagnep. 3 & white bract (cultivated) & P. Kohkaew 03/53 & spheroidal & $52.3 \pm 8.1$ & - \\
\hline C. alismatifolia Gagnep. 4 & purple bract (cultivated) & P. Kohkaew 04/53 & spheroidal & $56.8 \pm 5.0$ & - \\
\hline C. alismatifolia Gagnep. 5 & pink bract (cultivated) & P. Kohkaew 05/53 & spheroidal & $57.8 \pm 6.9$ & - \\
\hline C. alismatifolia Gagnep. 6 & pink bract (wild type) & P. Kohkaew 06/53 & subprolate & $53.2 \pm 5.8$ & $40.7 \pm 5.9$ \\
\hline C. angustifolia Roxb. & - & P. Kohkaew 07/53 & subprolate & $64.1 \pm 6.0$ & $50.9 \pm 6.9$ \\
\hline C. gracillima Gagnep. & - & P. Kohkaew 08/53 & subprolate & $59.2 \pm 6.1$ & $44.7 \pm 5.0$ \\
\hline C. harmandii Gagnep. & - & P. Kohkaew 09/53 & prolate spheroidal & $57.6 \pm 4.3$ & $53.5 \pm 4.6$ \\
\hline C. larsenii Maknoi \& Jenjitt & - & P. Kohkaew 10/53 & prolate spheroidal & $55.8 \pm 4.4$ & $51.2 \pm 4.5$ \\
\hline C. longa 1 & white bract & P. Kohkaew 19/53 & subspheroidal & $81.2 \pm 7.5$ & $61.8 \pm 6.3$ \\
\hline C. longa 2 & white with pink bract & P. Kohkaew 20/53 & prolate & $86.9 \pm 7.9$ & $62.6 \pm 7.1$ \\
\hline C. petiolata Roxb. & - & P. Kohkaew 11/53 & subprolate & $77.2 \pm 5.7$ & $58.5 \pm 7.3$ \\
\hline C. parviflora Wall. & - & P. Kohkaew 12/53 & prolate spheroidal & $50.7 \pm 3.7$ & $47.6 \pm 3.8$ \\
\hline C. cf. parviflora & - & P. Kohkaew 13/53 & prolate spheroidal & $50.7 \pm 3.7$ & $46.6 \pm 3.9$ \\
\hline C. pierreana Gagnep. & - & P. Kohkaew 14/53 & prolate & $65.1 \pm 5.8$ & $46.9 \pm 5.4$ \\
\hline C. rhabdota Sirirugsa \& Newman. & - & P. Kohkaew 15/53 & prolate spheroidal & $58.9 \pm 5.9$ & $55.2 \pm 6.1$ \\
\hline C. rubescens Roxb. & - & P. Kohkaew 23/53 & subspheroidal & $77.1 \pm 6.4$ & $65.5 \pm 4.1$ \\
\hline C. singularis Gagnep. & - & P. Kohkaew 16/53 & prolate spheroidal & $64.8 \pm 5.8$ & $58.9 \pm 6.0$ \\
\hline C. sparganifolia Gagnep. & - & P. Kohkaew 17/53 & prolate spheroidal & $50.5 \pm 3.4$ & $47.7 \pm 3.5$ \\
\hline
\end{tabular}

All specimens investigated are deposited at Mahasarakham University.

colours, i.e., white, yellow, red, purple, or bluish ${ }^{2}$. In the family Zingiberaceae, pollen morphology gives important data for their classification and systematics. Pollen morphology of Zingiberaceae has been studied by various researchers ${ }^{4-9}$. They used many characteristics of the pollen grain, i.e., shape, size, symmetry, and polar aperture to identify the species of plants. For the genus Curcuma, Chen and $\mathrm{Xia}^{10}$ have studied the pollen morphology of 14 species of Chinese Curcuma by SEM and transmission scanning microscopy (TEM). The present study was carried out in order to provide additional data for biological knowledge, identification and to present some palynological data, which would be useful for taxonomists who study or will study the family. No reports are currently available on pollen morphology for the genus Curcuma from Thailand.

\section{MATERIALS AND METHODS}

Pollen grains from 20 taxa of the genus Curcuma were collected from the fields with soil rich in humus located in mixed deciduous forest in Northeastern Thailand. The pollen grains were examined by light microscopy (LM) and scanning electron microscopy (SEM) (Table 1). The pollen was obtained from alcohol-preserved material. Samples were dehydrated using an alcohol series of 70\%, 80\%, 95\%, and $100 \%$. For LM studies, pollen grains were mounted in silicone oil and sealed with paraffin.
At least 30 pollen grains of each specimen were measured to determine the pollen-diameter $(\mu \mathrm{m})$ and then photographed using the LM (OLYMPUS BX50). For SEM studies, pollen grains in absolute alcohol were dried and affixed to aluminium stubs with double-sided cellophane tape. Samples were sputter-coated with a gold-palladium, examined and then photographed in the SEM (JEOL: JSM 6460 LV). Voucher specimens and all corresponding microscope slides were deposited at the Department of Biology, Faculty of Science, Mahasarakham University, Mahasarakham, Thailand. The terminology used with the pollen follows Punt et $\mathrm{al}^{11}$.

\section{RESULTS}

The pollen grains of all species are monad, inaperturate, apolar, with radial symmetry, and rugulose exine sculpturing. The size of the pollen grains varies from $50.5 \pm 3.4 \mu \mathrm{m}$ in $C$. sparganifolia to $86.9 \pm 7.9 \mu \mathrm{m}$ in C. longa 2 (Table 1, Figs. 1-3). The pollen grains of some species have aperture-like structures recognized as ridges or furrows such as in C. alismatifolia 3 and C. pierreana.

The pollen of the genus Curcuma in Thailand can be divided into 5 groups based on their shape as follows: Prolate spheroidal, including C. alismatifolia 1, C. harmandii, C. larsenii, C. parviflora, C. cf. parviflora, C. rhabdota, C. singularis, and C. sparganifolia; subprolate, including C. alismatifo- 

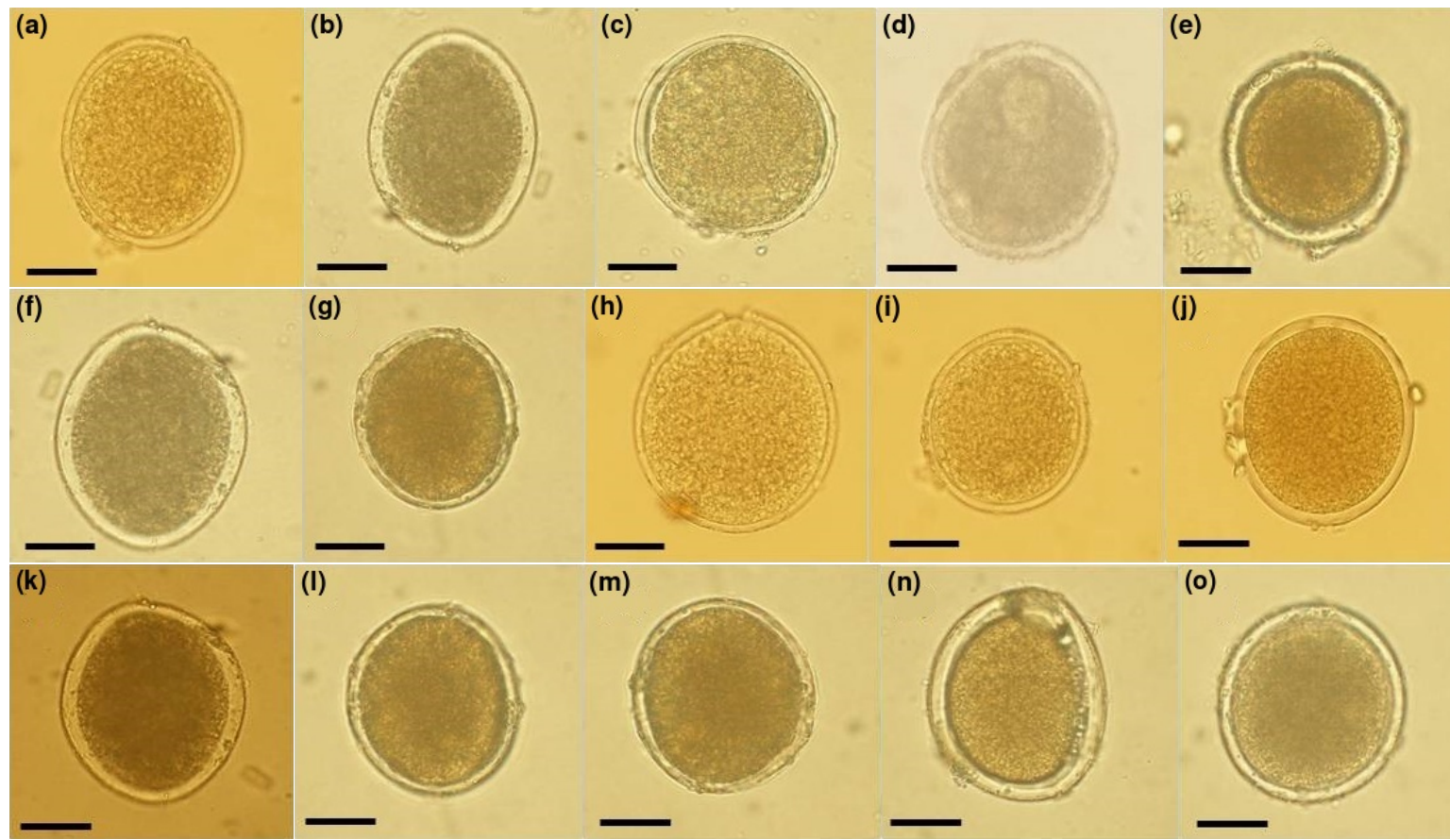

(m)

(p)

(q)

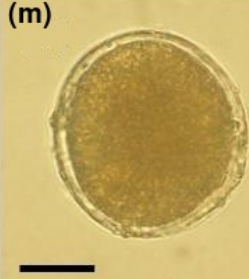

(i)
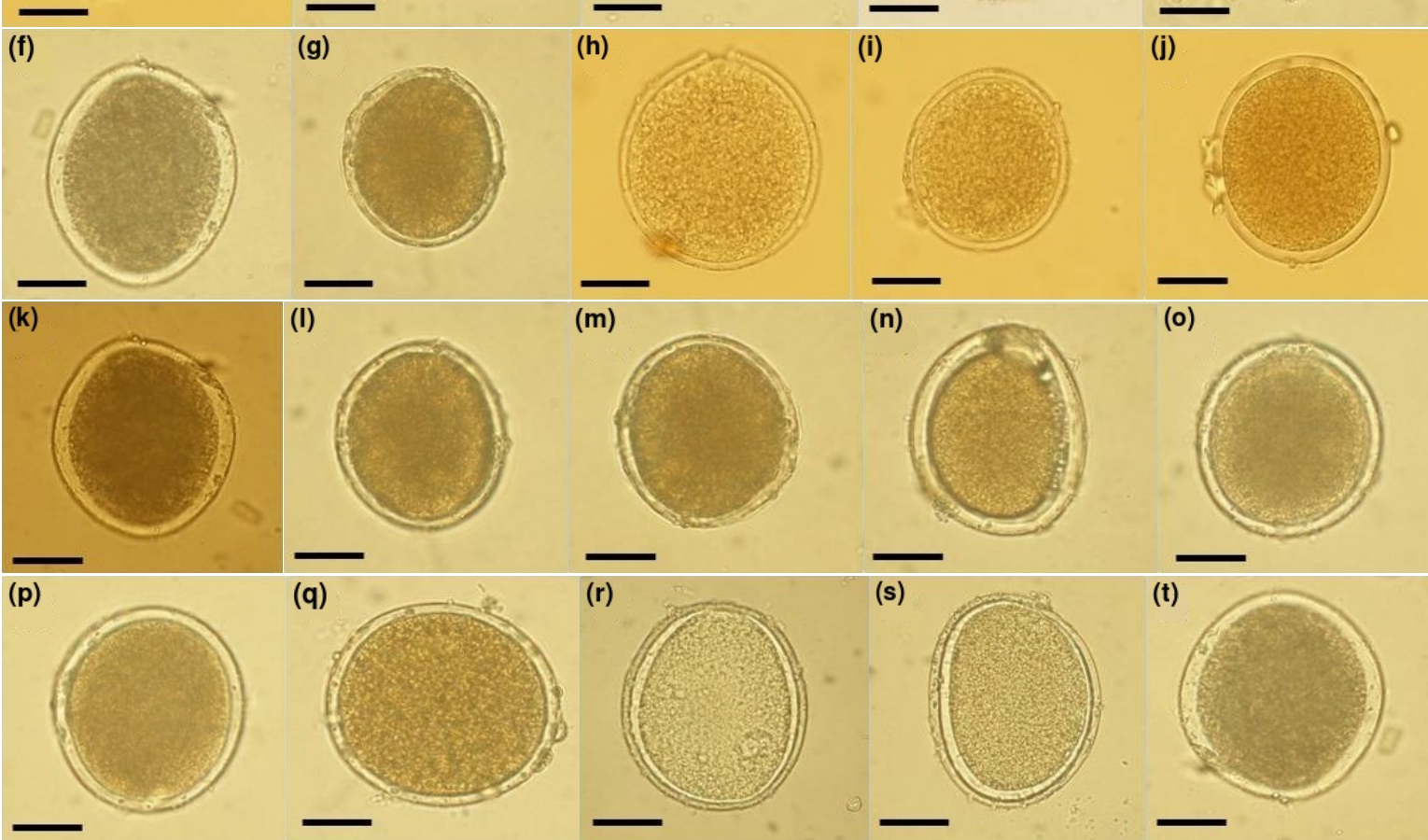

(o)

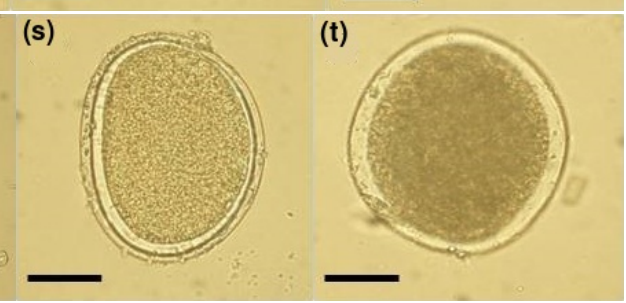

Fig. 1 Light micrographs of pollen from the genus Curcuma. (a) C. alismatifolia 1; (b) C. alismatifolia 2; (c) C. alismatifolia 3; (d) C. alismatifolia 4; (e) C. alismatifolia 5; (f) C. alismatifolia 6; (g) C. angustifolia; (h) C. gracillima; (i) C. harmandii; (j) C. larsenii; (k) C. longa 1; (l) C. longa 2; (m) C. petiolata; (n) C. parviflora; (o) C. cf. parviflora; (p) C. pierreana; (q) C. rhabdota; (r) C. rubescens; (s) C. singularis; (t) C. sparganifolia. Scale bars $=20 \mu \mathrm{m}$.

lia 2, C. alismatifolia 6, C. angustifolia, C. gracillima, and C. petiolata; spheroidal, including C. alismatifolia 3, C. alismatifolia 4, and C. alismatifolia 5; subspheroidal, including $C$. longa 1 and $C$. rubescens; prolate, including $C$. longa 2 and $C$. pierreana.

\section{DISCUSSION}

The pollen wall is composed of thin exine and thick intine, which is similar to that of most genera in Zingiberaceae $4-10,12,13$. The majority of the genus has large sized pollen in the range 50.5-86.9 $\mu \mathrm{m}$.

These results are in agreement with those of Maknoi $^{3}$, who divided the genus Curcuma into 5 groups based on morphological characters: 'Alismatifolia', 'Cochinchinensis', 'Ecomata', 'Longa', and 'Petiolata' groups. The alismatifolia group is composed of $C$. alismatifolia, C. gracillima, C. harmandii, C. parviflora, C. rhabdota, C. sparganiifolia, and C. larsenii. The cochinchinensis group includes $C$. cochinchinensis and $C$. pierreana. The Ecomata group is composed of C. bicolor, C. ecomata, C. flaviflora, C. glans, C. singularis, and C. stenochila. The petiolata group includes $C$. aurantiaca, C. petiolata, C. roscoeana, and $C$. rubrobracteata. The longa group consists of C. aeruginosa, C. amada, C. angustifolia, C. aromatica, C. comosa, C. latifolia, C. leucorhiza, C. longa, C. mangga, C. rubescens, C. viridiflora, C. xanthorrhiza, and $C$. zedoaria. The key characters used in this grouping are the leaf-base, bract apex, bracteole, coma bract, flower shape, anther spurs, and stylodes. The most important one is anther spurs, which is unique in each group. The pollen of the wild-type and cultivated C. alismatifolia from various locations also exhibit differences in the shape. The pollen morphology of C. alismatifolia 1, C. alismatifolia 2, C. alismatifolia 3, C. alismatifolia 4, 

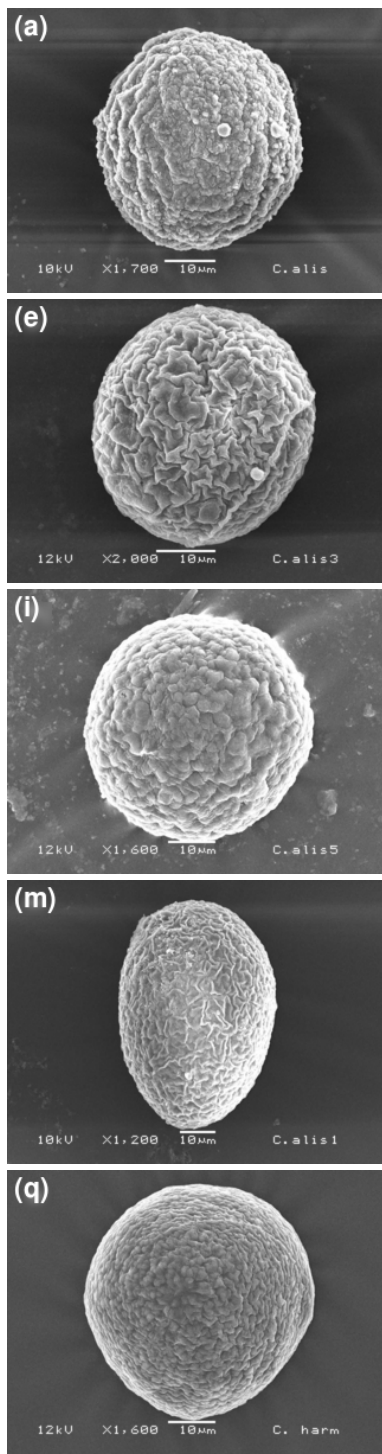
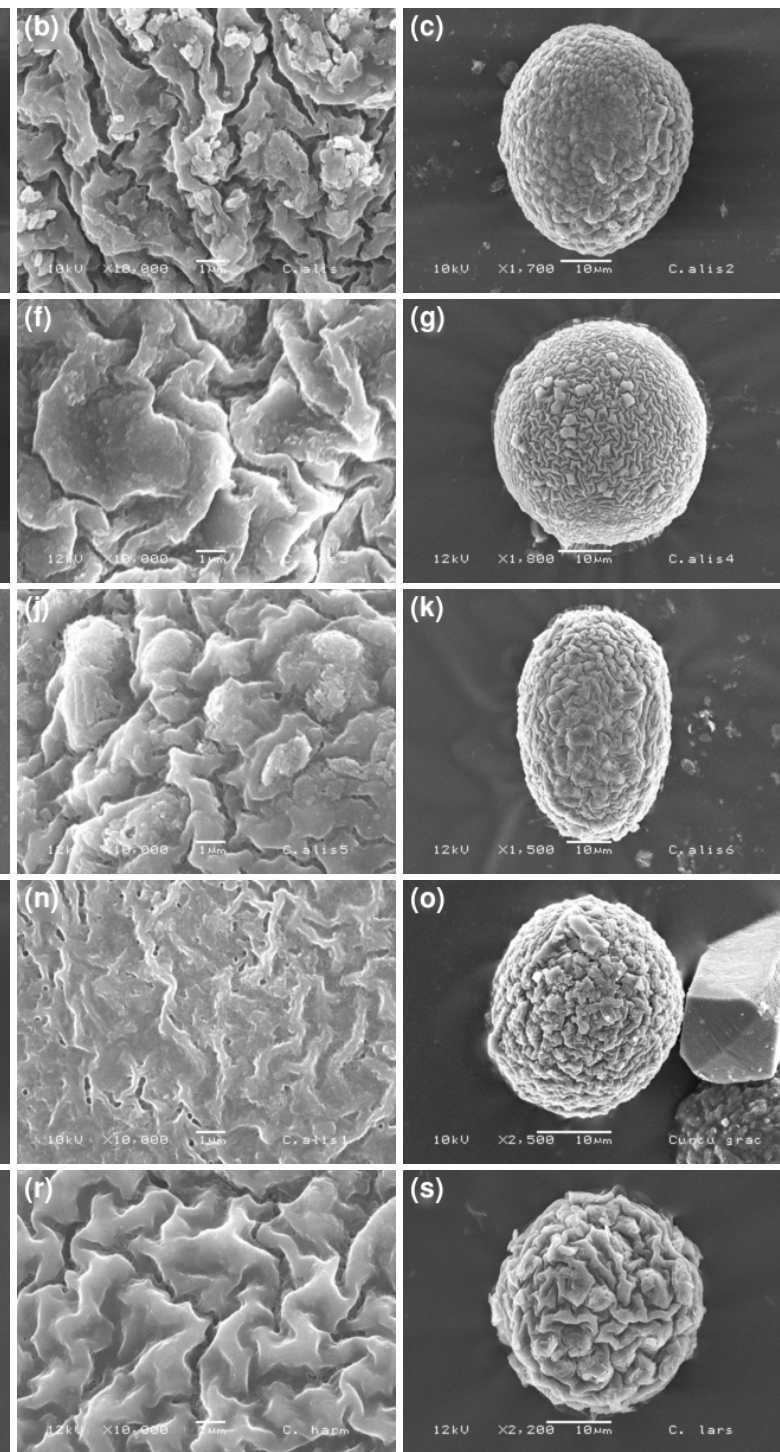
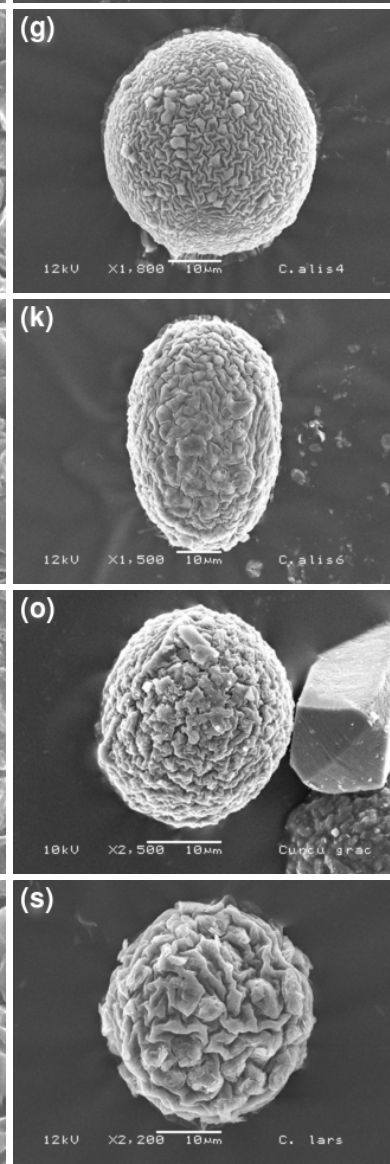
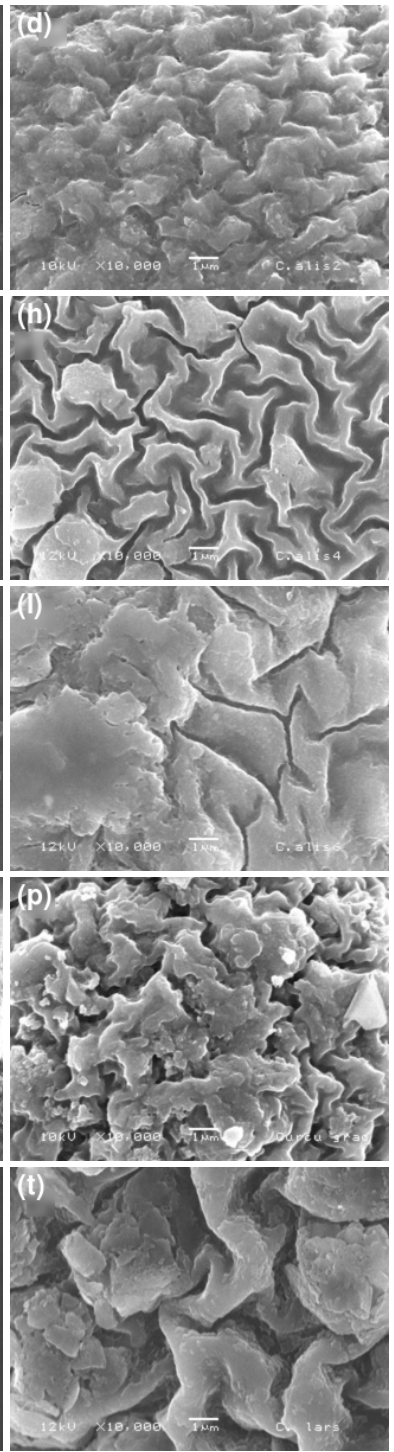

Fig. 2 Scanning electron micrographs of pollen from the genus Curcuma. Pollen grain: (a), (c), (e), (g), (i), (k), (m), (o), (q), (s). Exine sculpturing: (b), (d), (f), (h), (j), (l), (n), (p), (r), (t). (a,b) C. alismatifolia 1; (c,d) C. alismatifolia 2; $(\mathrm{e}, \mathrm{f})$ C. alismatifolia 3; (g,h) C. alismatifolia 4; (i,j) C. alismatifolia 5; (k,l) C. alismatifolia 6; (m,n) C. angustifolia; (o,p) C. gracillima; (q,r) C. harmandii; (s,t) C. larsenii.

C. alismatifolia 5, and C. alismatifolia 6 are quite similar, except for the pollen shape. Pollen grains of all C. alismatifolia are variously shaped, prolate spheroidal, spheroidal, and subprolate. These results may be due to the environmental conditions when the plant was growing in the field. Chen and $\mathrm{Xia}^{10}$ studied the pollen morphology of 14 species of Chinese Curcuma under SEM and TEM. The results showed that pollen grains of all Curcuma investigated are ovoid, inaperturate with psilate sculpturing. The pollen wall is composed of a very thin exine and a thick intine. Chen ${ }^{14}$ also reported the exine sculpturing of the pollen of Curcuma is psilate. In our study, the exine is rugulose. The results reveal morphological congruence between the pollen grains of species of Curcuma, which according to DNA sequence data appears to be a polyphyletic genus. The uniform pollen morphology in Curcuma however provides no evidence to divide this genus into separate taxonomic entities. The groups based on palynological characters, however, differ from the groups based on morphological char- 

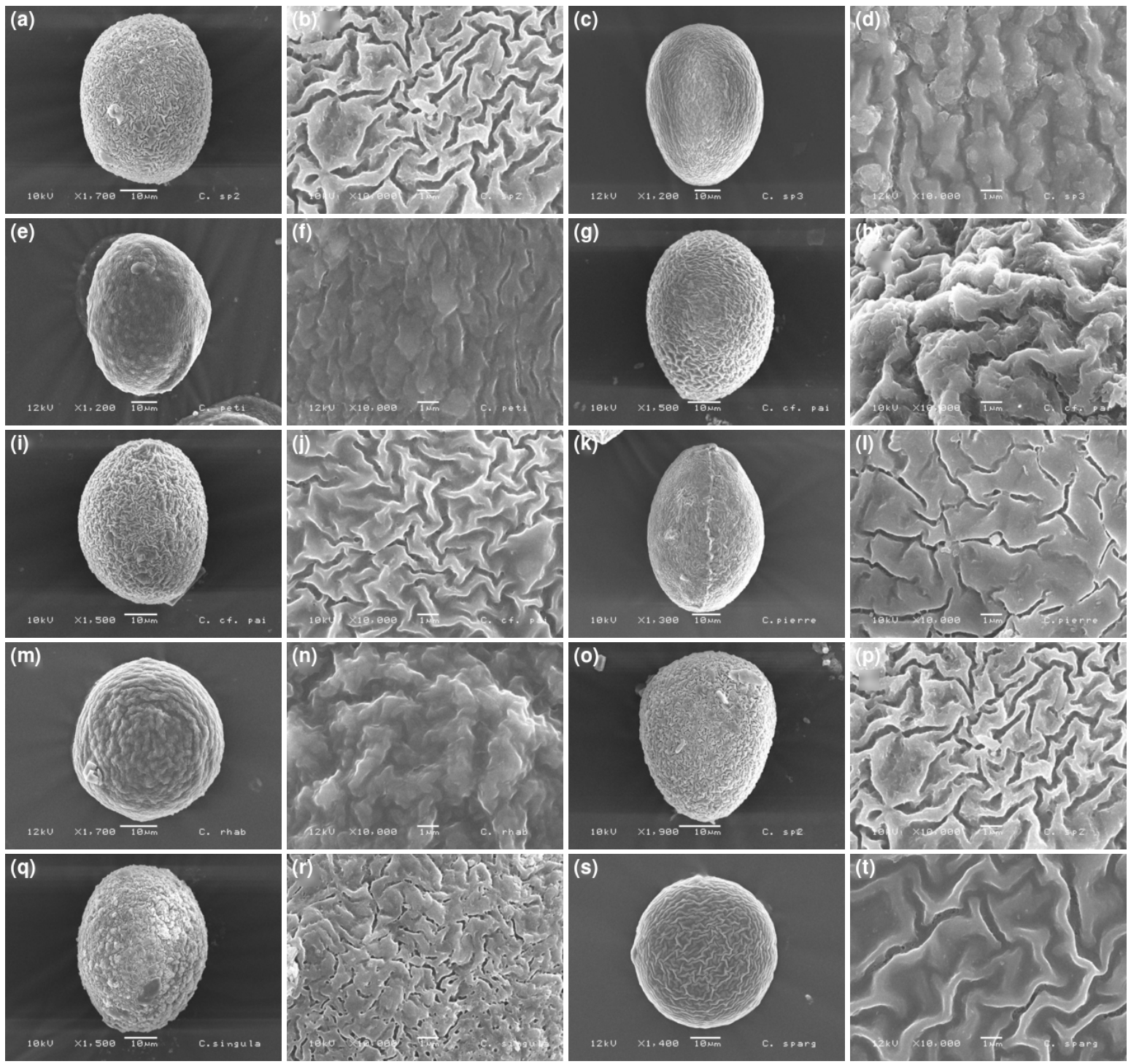

Fig. 3 Scanning electron micrographs of pollen from the genus Curcuma. Pollen grain: (a), (c), (e), (g), (i), (k), (m), (o), (q), (s). Exine sculpturing: (b), (d), (f), (h), (j), (l), (n), (p), (r), (t). (a,b) C. longa 1; (c,d) C. longa 2; $(\mathrm{e}, \mathrm{f})$ C. petiolata; (g,h) C. parviflora; (i,j) C. cf. parviflora; (k,l) C. pierreana; (m,n) C. rhabdota; (o,p) C. rubescens; (q,r) C. singularis; $(\mathrm{s}, \mathrm{t})$ C. sparganifolia.

acters. More research using molecular data and population genetic studies is needed to investigate the relationships in the genus Curcuma.

Acknowledgements: This study was supported by the Thailand Research Fund, Office of the Higher Education Commission and Mahasarakham University (MRG5380166). We are especially grateful to the Department of Biology, Faculty of Science, Mahasarakham University and the Central Instrumentation Unit of Faculty of Science, Mahasarakham University for the facilities.
The authors are indebted to Dr Jolyon Dodgson for his review and correction of the manuscript.

\section{REFERENCES}

1. Kress WJ, Prince LM, Williams KJ (2002) The phylogeny and a new classification of the gingers (Zingiberaceae): evidence from molecular data. $A m J$ Bot 89, 1682-96.

2. Larsen K, Larsen SS (2006) Gingers of Thailand, Queen Sirikit Botanic Garden, Chiang Mai.

3. Maknoi J (2006) Taxonomy and phylogeny of the 
genus Curcuma L. (Zingiberaceae) with particular reference to its occurrence in Thailand. $\mathrm{PhD}$ thesis, Prince of Songkla Univ.

4. Erdtman G (1969) Pollen Morphology and Plant Taxonomy: Angiosperms (An Introduction to Palynology I), Heffner Publishing, London.

5. Nair PKK (1971) Pollen Morphology of Angiosperms: A Historical and Phylogenetic Study, Barnes \& Noble, New York.

6. Liang YH (1988) Pollen morphology of the family Zingiberaceae in China-pollen types and their significance in the taxonomy. Acta Phytotax Sin 26, 265-86, [in Chinese].

7. Moore PD, Webb JA, Collinson ME (1991) Pollen Analysis, Blackwell Scientific, Oxford.

8. Theilade I, Mærsk-Møller ML, Theilade J, Larsen K (1993) Pollen morphology and structure of Zingiber (Zingiberaceae). Grana 32, 338-42.

9. Saensouk P, Chantaranothai P, Theerakulpisut P (2009) Pollen morphology of the genus Cornukaempferia (Zingiberaceae) in Thailand. $J$ Systemat Evol 47, 139-43.

10. Chen J, Xia NH (2011) Pollen morphology of Chinese Curcuma L. and Boesenbergia Kuntz (Zingiberaceae): taxonomic implications. Flora 206, 458-67.

11. Punt W, Hoen PP, Blackmore S, Nilsson S, Le Thomas A (2007) Glossary of pollen and spore terminology. Rev Palaeobot Palynol 143, 1-81.

12. Mangaly JK, Nayar J (1990) Palynology of South Indian Zingiberaceae. Bot J Linn Soc 103, 351-66.

13. Saensouk S (2006) Taxonomy and biology of the genus Alpinia Roxb. (Zingiberaceae) in Thailand. $\mathrm{PhD}$ thesis, Khon Kaen Univ.

14. Chen ZY (1989) Evolutionary patterns in cytology and pollen structure of Asian Zingiberaceae. In: Holm-Nielsen LB, Nielsen IC, Balslev H (eds) Tropical Forests: Botanical Dynamics, Speciation and Diversity, Academic Press, pp 185-91. 